\title{
PROFESSORES TUTORES E A FLEXIBILIZAÇÃO DO TEMPO DE TRABALHO
}

\author{
Felipe Teófilo Ponte \\ Núcleo de Psicologia do Trabalho - Universidade Federal do Ceará
}

\author{
Cássio Adriano Braz de Aquino
}

Universidade Federal do Ceará

\begin{abstract}
Resumo
O artigo buscou investigar o modo como os professores tutores vivenciam a temporalidade laboral, numa área em que as tecnologias alteram a ideia de presencialidade. Com base nisso, salienta-se que a relação tempo/trabalho se tornou um âmbito privilegiado de análise dessa investigação, compreendendo as mudanças na realidade laboral, bem como suas repercussões para o contexto da Educação. O processo de flexibilização, revelado nos discursos destes profissionais, aufere destaque no recorte deste estudo. Com base na abordagem qualitativa, e utilizando-se da Sóciohermenêutica, foram realizadas entrevistas semiestruturadas com 11 tutores. Percebeu-se que as jornadas tradicionais, caracterizadas pela linearidade, dão lugar a períodos de trabalho mais fragmentados e individualizados. O uso das tecnologias, no exercício de tutoria, sugere certa autonomia na organização individual das atividades a serem executadas, entretanto, a noção que o trabalhador tem de ausência de controle se torna 'ilusória', uma vez que esse aspecto se manifesta sutilmente.

Palavras-chave: Educação a Distância; Flexibilização; Tempo Social; Trabalho.
\end{abstract}

\section{ONLINE TEACHERS AND WORKING HOURS FLEXIBILITY}

\begin{abstract}
This article aimed to investigate how online teachers experience work temporality, in an area in which technologies have changed the idea of presence. It is emphasized then, that time/work relationship has become a privileged area for the analysis of this research including changes in labor reality, as well as its repercussions for the Education context. The process of flexibility, revealed how the discourses of such professionals, is highlighted in this study. Based on the qualitative approach, and using sociohermeneutics, semi-structured interviews were carried out with 11 tutors. It was noticed that the traditional journeys, characterized by linearity, give rise to more fragmented and individualized work periods. As far as tutoring practice is concerned, the use of tecnologies, sugests certain autonomy when it comes to organizing individual activities to be performed. But, the worker's awareness of lack of control has become unrealistic once such aspect has has been slightly stated.
\end{abstract}

Keywords: Distance Education; Flexibility; Social Time; Job.

\section{LOS PROFESORES TUTORES Y LA FLEXIBILIDAD DEL TIEMPO LABORAL}

\section{Resumen}

El artículo objetiva investigar como los profesores tutores experimentan la temporalidad laboral, en un contexto donde las tecnologías cambian la idea de presencialidad. A partir de esto, se observa que la relación entre el tiempo y el trabajo se convirtió en un marco privilegiado de análisis de esta investigación. El proceso de flexibilización, revelado en los discursos de estos profesionales adquiere recorte de relieve. Partiendo del enfoque cualitativo, y haciendo uso de la socio-hermenéutica, fueran aplicadas entrevistas semiestructuradas con 11 profesores tutores. Se observó que la organización de la jornada laboral tradicional, caracterizada por la linealidad, ha dado lugar a períodos de trabajo más fragmentados e individualizados. El uso de la tecnología en el ejercicio de tutoría sugiere una cierta autonomía en la organización individual de las actividades, sin embargo, esta percepción no es de todo verdadera, ya que este aspecto se expresa sutilmente.

Palabras clave: Aprendizaje a Distancia; Flexibilidad; Tiempo Social; Trabajo. 


\section{INTRODUÇÃO}

Este estudo, ao lidar com a relação entre professores tutores e temporalidade laboral, situa-se num território demarcado, fundamentalmente, pelo intenso uso das tecnologias de informação e de comunicação (TIC) no processo educacional e pela forte inserção de estratégias flexíveis no modo de organização do trabalho.

O componente informacional, durante os anos de 1960, se fez base material de uma nova organização social, intitulada por Castells (1999) de sociedade da informação. Neste contexto, as tecnologias de informação e de comunicação (TIC) auferem um papel de destaque, passando a ser compreendidas não apenas como recursos ou meios, mas como elementos constituintes das relações de experiência, de poder e de cultura (Lévy, 2011). A dinâmica destes processos e as consequências produzidas por eles "ajudaram" a imprimir um novo indicativo referente aos modos da gestão e ao valor moral atribuído ao trabalho.

É sabido que as relações laborais se edificam por meio da técnica. Existe uma recíproca dependência entre esses dois aspectos (Coriat, 1976). Se a racionalização permite ao trabalhador a redução do tempo de trabalho, 0 aumento da velocidade na execução das atividades e a simplificação de suas tarefas, agora, favorece, também, o desenvolvimento de uma organização de trabalho mais flexível (Harvey, 2008). Apesar de uma ampla e complexa compreensão acerca da flexibilidade, a flexibilização laboral é qualificada aqui como um conjunto de estratégias gerenciais que tornam mais maleáveis as normas e práticas que regem uma determinada organização de trabalho (Miguélez, 2004). Não se deve perder de vista, porém, a noção de que existe estreita relação entre este fenômeno e a fragilização e/ou desarticulação da proteção trabalhista (benefícios sociais e previdenciários) (Antunes, 2015).

O avanço desse modelo de trabalho no panorama global pode estar associado à expansão das políticas neoliberais, uma estratégia de enfrentamento à chamada crise econômica dos anos de 1970, período marcado, principalmente, pelo aumento da concorrência, em vista da saturação do mercado interno da Europa e da Ásia, pela desregulamentação do sistema monetário internacional; com o declínio da moeda estadunidense e pela crise do petróleo, que teve seus preços aumentados no contexto internacional (Antunes, 2005; Nardi, 2006; Sennet, 2006).

A expansão das políticas neoliberais se deu em contraste relacionado aos princípios socioeconômicos dominantes na sociedade industrial, cuja prioridade se volta para o intenso controle sobre os meios de produção, a maior rigidez na operacionalização da dinâmica produtiva e a utilização de grande quantidade de funcionários, os quais executam trabalhos repetitivos, mecânicos e especializados. Esse novo método, originado na empresa Toyota, do Japão, nos 
anos de 1950, visou à organização laboral pautada na implementação de trabalhadores mais versáteis, na redução da mão de obra lean production, numa produção baseada na demanda de mercado just in time e na personalização dos produtos (Alves, 2011; Garrido, 2006; Nardi, 2006).

Nesse paradigma, ocorre a extinção daquelas tarefas repetitivas, simplificadas e fragmentadas, assim como da divisão entre trabalho físico e labor intelectual, características predominantes no modelo industrial. Agora, o trabalhador é cobrado a se tornar uma mão de obra que crie e operacionalize o trabalho. Exige-se dele saber trabalhar em equipes multifuncionais de cooperação mútua e, continuamente, estar desenvolvendo sua formação profissional (Lojkine, 1995; Alves, 2007).

Ernst (2003) explica que aquelas prerrogativas de controle, regularidade e uniformidade, centrais no paradigma industrial, se tornaram menos hegemônicas nessa realidade contemporânea, o que desencadeou o surgimento de demarcações constitutivas na estruturação dos tempos laborais. Com base nisso, precisa-se compreender que a ideia central acerca de um quadro temporal marcado por uma suposta fixidez do espaço e dos intervalos de tempo perde força no contexto sociolaboral de hoje. Tal característica favorece a criação de uma variabilidade de horários que permite aos trabalhadores se organizarem conforme sua disponibilidade (Grisci, 2008).

Será, entretanto, que essa suposta maleabilidade de organizar seus horários de trabalho conforme sua disponibilidade é um aspecto tão positivo neste contexto da flexibilização?

As categorias tempo e trabalho são compreendidas, neste estudo, com alicerce na teoria dos tempos sociais (Beriáin, 2009; Gasparini, 1996; Sue, 1995), mediante a ideia que associa o ordenamento da temporalidade social a uma configuração temporal dominante (sua duração, valor, representação e outros fatores). Desse modo, o trabalho, situado no período pós-Revolução Industrial, é deslocado para um lugar de destaque na ordem social, tornando-se um balizador da organização dos tempos sociais (Aquino, 2009).

A relação entre tempo e trabalho, compreendida como central na estruturação da dinâmica temporal, torna-se um fio condutor para se entender as alterações na configuração das relações laborais, além de ocupar um papel fundamental para se vislumbrar os novos estilos de vida que surgem no cotidiano do trabalhador e que pode ser observado nas novas modalidades de organização do processo educacional. O contexto da Educação a Distância (EAD), dentre os mais diversos âmbitos institucionais, representa um espaço privilegiado para este estudo, por entender-se que essa configuração educacional incorpora aspectos que ilustram melhor a atual realidade caracterizada por mudanças que envolvem o tempo de trabalho, tendo em vista as repercussões da flexibilização.

A Educação a Distância é uma modalidade da área educacional que deve ser vista como algo complexo e dinâmico. Importante é lembrar que essa 
terminologia representa um conceito genérico que incorpora inúmeras metodologias de ensino e de aprendizagem. Salienta-se que um ponto possível de considerar como central, na tentativa de compreensão desse fenômeno, se refere à sua proposta pedagógica, que se baseia no fato do professor e do aluno não precisarem compartilhar do mesmo tempo e espaço (Mill, 2012).

Salienta-se que a característica de Educação a Distância (EAD) priorizada neste estudo é a on-line. Ela é compreendida como aquela modalidade educacional, cujas atividades de ensino e aprendizagem ocorrem, predominantemente, por meio do uso de tecnologias de informação e comunicação (internet e outros) (Lencastre, 2012). Neste âmbito, o paradigma estruturado por via do tripé sala de aula, professor e aluno é objeto de uma mudança na sua maneira de interação, em comparação às características do ensino presencial. Este aspecto representa um novo fato, não somente para a Educação, mas também para as relações de trabalho estabelecidas (Belloni, 2003; Preti, 1996).

A exemplo disso, destacam-se as relações de trabalho do professor, que se reorganizam com base em novas atribuições e outros papeis, dentre os quais chama a atenção o exercício da tutoria a distância, uma função cujas atividades, implicadas ao uso de tecnologias de informação e de comunicação (telefonias, computadores etc.), se desenvolvem, prioritariamente, numa temporalidade assíncrona e num ambiente deslocável (Mill, 2012). Segundo explicitado na Resolução do Fundo Nacional de Desenvolvimento da Educação (FNDE) no 8, de 30 de abril de 2010, o tutor é um profissional escolhido pela instituição de Ensino Superior integrada ao sistema Universidade Aberta do Brasil (UAB), que precisa ter formação de nível superior e experiência necessária de um ano de magistério, seja no ensino básico ou superior.

Cabe esclarecer, ainda, que a Universidade Aberta do Brasil (UAB), criada em 2005 pelo Ministério da Educação (MEC), é um programa que tem por finalidade promover a integração do sistema nacional de Educação Superior a Distância com as universidades públicas. Esta medida visa a expandir a oferta de cursos de ensino superior no Território Brasileiro, tendo em vista "alcançar" segmentos da população que têm dificuldade de conseguir uma formação universitária (Zuin, 2006).

Trazer os discursos de um grupo de trabalhadores, que se denominaram professores tutores, cujo modo de vivenciar a temporalidade laboral é diferenciada daquela estrutura temporal tradicionalmente experimentada na sociedade industrial (sistema taylorista-fordista), e também da Educação presencial, se torna um âmbito privilegiado de análise desta investigação. Deste modo, esses aspectos elencados, contribuem para se poder entender certas mudanças na realidade laboral, bem como suas repercussões para o contexto educacional. 


\section{MÉTODO}

Este artigo está ancorado nos dados empíricos de uma pesquisa de Mestrado, intitulada "O (re)dimensionamento da temporalidade laboral na vivência de professores tutores da educação on-line" (Ponte, 2015), cujo projeto foi aprovado pelo Comitê de Ética em Pesquisa da Universidade Federal do Ceará (CEP/UFC) (CAAE 34103714.5.0000.5054).

Para o desenvolvimento desta investigação, foi utilizada a metodologia qualitativa (Bauer \& Gaskell, 2002), com referência à Psicologia Social do Trabalho. Nessa conjuntura, a realidade social passou a ser estudada mediante a inclusão da práxis do sujeito que, por meio de sua ação e das articulações que estabelece com o meio, produz significados e modalidades de interpretação desse âmbito. O ser humano, então, é visto como um ser em interação, que modifica o mundo e é modificado por este (Sato, Bernardo \& Oliveira, 2008).

Para isso, delimita-se o campo de pesquisa, ao âmbito dos trabalhadores que estão vinculados à política pública da Universidade Aberta do Brasil (UAB), ou seja, ao campo dos cursos de Ensino Superior a distância. São professores tutores que atuam em cursos de graduação semipresencial, numa instituição de Ensino Superior pública na cidade de Fortaleza/CE.

Os cursos se estruturam conforme a seguinte carga horária: $80 \%$ (oitenta por cento) acontecem por meio do Ambiente Virtual de Aprendizagem e $20 \%$ (vinte por cento) sucedem presencialmente. As aulas presenciais são realizadas nos municípios integrados ao sistema Universidade Aberta do Brasil (UAB). Assim, esses encontros podem ocorrer na capital, Fortaleza/CE, ou em um dos polos do interior do Estado, a depender da localização do discente.

O recorte preciso desse grupo investigado considerou as características dos tutores que aí situados e justificou-se pelo fato de se evidenciarem, neste âmbito de atuação, traços e/ou aspectos que caracterizam a reestruturação do tempo de trabalho, produto tanto das mudanças ocorridas nas jornadas laborais como fruto do surgimento de outras configurações de vínculos de trabalho. 0 recrutamento desses agentes participantes da pesquisa aconteceu, ainda, com o auxílio das coordenações dos cursos presenciais. Houve agendamento com os coordenadores, a fim de que pudessem ser apresentadas as propostas (informar as principais diretrizes do projeto) e solicitar o acesso aos profissionais a quem se dirige a investigação.

A aproximação ocorreu sob duas modalidades: na primeira, eles foram convidados via telefone e, na seguinte, a proposta se deu por meio do encaminhamento de um convite. Além disso, é importante frisar que também houve, para alguns casos, a utilização da técnica bola de neve, em que os próprios entrevistados indicavam outros professores tutores que poderiam participar da pesquisa. Acrescenta-se, ainda, a informação de que cada 
participante foi informado acerca do trâmite do estudo e assinou o Termo de Consentimento Livre e Esclarecido (TCLE).

Com procedência nesse, optou-se por professores tutores que tivessem, pelo menos, um ano no exercício da prática a distância. Essa duração mínima tinha por intuito estabelecer um parâmetro que viabilizasse trabalhar com profissionais que expressassem uma vivência razoavelmente significativa no exercício da função de tutor na estrutura de Educação a Distância. Por ser este um estudo qualitativo, a saturação do conteúdo representou um aspecto fundamental para a definição do número de entrevistas, pois se reconhece que o mais significativo nas pesquisas qualitativas é a maneira como se concebem a representatividade dos dados e a qualidade das informações obtidas dos pesquisados (Fontanella, Ricas, \& Turato, 2008).

Os participantes desse estudo foram 11 , sendo 8 do sexo feminino e três do masculino. Eles, na realidade, acumulam, preponderantemente, um vínculo de trabalho, além da Educação a Distância. A Tabela 1 apresentada ilustra esta realidade.

Tabela 1.

Acúmulo de vínculos laborais dos professores tutores entrevistados

\begin{tabular}{|c|c|c|}
\hline $\begin{array}{l}\text { Professores } \\
\text { tutores }\end{array}$ & Sexo $(M$ ou $F)$ & Outro vínculo laboral, além da EaD \\
\hline $\mathrm{T} 1$ & $\mathrm{~F}$ & Professora efetiva / Professora temporária \\
\hline $\mathrm{T} 2$ & M & Professor efetivo / Coordenação de curso \\
\hline T3 & M & Professor temporário \\
\hline $\mathrm{T} 4$ & $\mathrm{~F}$ & $\begin{array}{l}\text { Professora temporária / Professora tutora } \\
\text { (outra instituição) }\end{array}$ \\
\hline T5 & $\mathrm{F}$ & Pós-graduação em andamento (Mestrado) \\
\hline T6 & $\mathrm{F}$ & $\begin{array}{l}\text { Professora temporária / Pós-graduação em } \\
\text { andamento (Doutorado) }\end{array}$ \\
\hline T7 & $\mathrm{F}$ & $\begin{array}{l}\text { Professora temporária / Pós-graduação em } \\
\text { andamento (Doutorado) }\end{array}$ \\
\hline T8 & $\mathrm{F}$ & $\begin{array}{l}\text { Professora efetiva / Professora temporária / } \\
\text { Pós-graduação em andamento (Doutorado) }\end{array}$ \\
\hline T9 & $\mathrm{F}$ & $\begin{array}{c}\text { Professora temporária / Pós-graduação em } \\
\text { andamento (Doutorado) }\end{array}$ \\
\hline T10 & M & $\begin{array}{l}\text { Professor temporário / Pós-graduação em } \\
\text { andamento (Especialização) }\end{array}$ \\
\hline $\mathrm{T} 11$ & $\mathrm{~F}$ & Ausência de outras atividades \\
\hline
\end{tabular}

A tabela foi dividida em três secções, na qual a primeira coluna representa o código de identificação dos professores tutores. A seguinte condiz ao recorte do sexo biológico dos participantes ( $\mathrm{M}$ : masculino e $\mathrm{F}$ : feminino) e, na última parte, 
tem-se a delimitação de outros vínculos de trabalho, além da Educação a Distância (isto quando o possuíam).

A coleta dos dados ocorreu por meio de entrevista do tipo semiestruturada, cuja organização foi guiada com base em um roteiro elaborado com três grandes tópicos elegidos como norteadores: jornada de trabalho, relação entre tempo de trabalho e tempo de não trabalho e experiência na área da EAD, os quais foram elaborados em consonância com a proposta do estudo, entender como esses profissionais da Educação a Distância on-line vivenciam o seu tempo de trabalho.

Outros recursos que ajudaram a realizar essa coleta de dados, do modo mais fidedigno possível, dizem respeito ao diário de campo e ao gravador de áudio (voz/som). No primeiro, foram anotadas as impressões que os entrevistados forneceram durante as entrevistas e, mesmo, além delas. O uso da segunda ferramenta possibilitou preservar a integridade do discurso, ampliando deste modo a quantidade de tópicos assimilados (Bauer \& Gaskell, 2002).

Realizada a coleta de dados, partiu-se para a análise, na qual se utilizou a metodologia de Alonso (1998), também conhecida por Análise Sóciohermenêutica. Esse método busca encontrar uma maneira de revelar os "ditos" e "não ditos" que perpassam o universo sociolinguístico de um contexto. É uma reconstrução crítica, ligada, principalmente, à situação e à contextualização histórica do discurso (Coelho, 2012; Ruiz, 2009).

Não se deve perder de vista a noção de que o território discursivo representa um campo multidimensional, que acolhe variadas modalidades de uso (Iñiguez, 2004). O método sócio-hermenêutico pode ser tido como uma delas. Essa possibilidade de análise do discurso é estruturada com base em três perspectivas, quais sejam: a análise informacional e quantitativa, a análise estrutural e textual e a análise sócio-hermenêutica (Alonso, 1998). Assim, procurou-se estruturar as etapas desta investigação por meio dos passos delineados na sequência.

Primeiro, buscou-se realizar leitura flutuante das informações transcritas, coletadas mediante as entrevistas. Então, utilizou-se a análise informacional e quantitativa, uma fase considerada mais descritiva, objetiva e semântica do processo. Nesta demandou-se captar padrões de palavras (frequência), com origem na segmentação do texto em unidades mínimas de significado. Com isso, tentou-se acessar o conteúdo manifesto do discurso, ou seja, a comunicação mais explícita, a informação imediata que os sujeitos têm sobre a realidade em que estão inseridos.

A seguir, empreendeu-se a análise estrutural e textual, uma etapa em que se procedeu à fragmentação do texto. Nesta fase do processo, visou-se a destacar eixos (estruturas) que auxiliassem a encontrar contextos mais singularizados (latente) do discurso. Essas comunicações mais implícitas podem ser consideradas um reflexo das ideologias que circundam os participantes. 
Por conseguinte, aplicou-se a análise sócio-hermenêutica. Nesta fase, buscou-se encontrar linhas argumentativas e pôr em diálogo com outras deste mesmo teor. Tal dinâmica era referenciada por Alonso (1998) como um movimento interacional de textos e contextos. Observou-se uma linha analítica que privilegia a relação dialética entre realidade e discurso, no qual a primeira edifica a segunda e, como a recíproca se aplica igualmente.

Salienta-se que essas fases de análise não representam um percurso linear, mas constituem uma dinâmica pois, constantemente, estão dialogando entre si (Ruiz, 2009). É importante destacar, também, a ideia de que os discursos não podem ser divisados isoladamente, mas articulados em sistemas (Conde, 2009). Essa maneira de olhar posiciona o pesquisador em um lugar, onde passa a perceber o texto além de um caráter meramente formal. A seguir discutir-se-ão melhor esses aspectos, que retrataram a integração dessas fases de análise.

\section{RESULTADOS E DISCUSSÃO}

A sistematização dos discursos, por meio do método de Análise Sóciohermenêutica, permitiu que os participantes da pesquisa atribuíssem sentidos aos acontecimentos que vivenciaram. Por meio desse percurso discursivo, delineia-se o processo interpretativo e categórico da pesquisa (Coelho, 2012).

Em tal percurso, os três tópicos norteadores da entrevista semiestruturada se converteram em categorias e, destas, emergiram outras matrizes sociolinguísticas em torno da temporalidade de trabalho, quais sejam: professores tutores num âmbito de racionalização do trabalho; a realidade do professor tutor e, por fim, professores tutores: percepções de si, no contexto de atuação da EAD. O ponto de partida da entrevista abordou a temática da jornada de trabalho, na qual os participantes da pesquisa exploraram os seguintes aspectos:

\section{Jornada de trabalho do Professor Tutor}

Os professores tutores entrevistados apontam, predominantemente, para uma estruturação de horários com formatos atípicos, quando comparada a uma distribuição da jornada integral/completa de trabalho (40 horas/semanais). De modo geral, destacaram que os períodos dedicados à execução das práticas de tutoria são flexíveis quanto à execução das atribuições e o manejo sobre o tempo.

\section{[...] Eu faço o meu próprio horário (T04).}

[...] Eu, geralmente, faço isso no final da manhã, perto do almoço ou então, à noite (T08).

[...] Não existe um horário fixo. Eu preciso me organizar de acordo com meu horário (T06). 
As tarefas desses profissionais podem ser executadas com inúmeras possibilidades de espaço e tempo, não existindo mais a necessidade imprescindível de a pessoa estar fisicamente no trabalho. Representa uma modalidade de ocupação, caracterizada, principalmente, por ser apoiada nos dispositivos tecnológicos e por denotar pessoas que desenvolvem atividades à distância, da instituição de ensino de que fazem parte (Alves, 2008).

Com suporte nessa conjuntura, surgem aqueles postos ocupacionais conhecidos como trabalhos móveis, àqueles que "[...] contrariam a ideia de emprego e de carreira em local fixo" (Grisci, 1999, p. 90). Essa configuração de trabalho, também chamada de teletrabalho, se desenvolve, predominantemente, fora do âmbito organizacional, podendo ser desempenhada em casa, no carro, no aeroporto, ou mesmo em outro trabalho que a pessoa venha a ter.

O termo teletrabalho foi, inicialmente, empregado por Nilles (1976), na década de 1970. Originado da palavra inglesa telework ou telecommunication (tele que vem do grego $T \eta \lambda \varepsilon$, cujo significado é longe/distância), o referido autor popularizou essa expressão mediante a publicação da obra The Telecommunications - Transportation: Options for Tomorrow. Neste livro, ele aborda, como eixo central, a ideia de um trabalho deslocável para os trabalhadores. Em outras palavras, consiste em levar o trabalho aos trabalhadores, em vez do contrário. O objetivo do estudo era demonstrar quais os influxos que a redução e/ou eliminação das viagens diárias ao trabalho acarretaram na gestão, na produtividade, custos e benefícios de uma determinada organização laboral estadunidense.

Nesse sentido, a concepção desse termo se aplica àqueles trabalhadores que desempenham suas atividades com o auxílio do uso das tecnologias de informação e comunicação (TIC), de maneira a romperem perspectivas espaciais tão fortemente delimitadas pelos ambientes de trabalho convencionais e, ao mesmo tempo, ter em mãos o recurso necessário, a fim de comunicarem os resultados atingidos (computadores, telefones móveis e outros) (Nilles, 1976).

Os professores tutores destacaram o fato de que o uso de computadores e aparelhos de telefonia móvel, durante a realização das tarefas de tutoria, permite que eles não precisem se deslocar para a instituição de ensino a fim de marcar o cartão de ponto. Além disso, sua comunicação com os coordenadores ou suporte técnico, em caso de dúvidas e/ou alguma solicitação, ocorre mediante a utilização da internet.

[...] Você trabalha em casa, no conforto do seu quarto, na sua cama. E pegar o notebook, enquanto você está com uma panela no fogo, e vai respondendo uma tarefa ou um fórum, ou um chat. A vantagem é a flexibilidade (T01).

[...] Eu entro no sistema às $10 \mathrm{~h}$ da manhã, então coloco: - Estou disponível. Deixo o notebook ligado e vou fazendo algumas coisas em casa; também realizo algumas pesquisas para encaminhar para eles, etc (T11). 
Conforme Masi (2001), nessa estrutura laboral, os bens produzidos estão menos conectados a um lugar e a um tempo. Existe o rompimento do espaço físico do escritório e dos muros da fábrica, ao mesmo instante em que as atividades estão, prioritariamente, vinculadas ao uso de dispositivos tecnológicos.

Nessa modalidade de trabalho, pode-se mencionar como uma vantagem a própria flexibilização do tempo e do espaço das relações laborais, uma vez que ela favorece a interação com um número maior de grupos culturais, reduz os problemas de mobilidade social (questões relativas ao deslocamento urbano), auxilia o processo de inclusão social e traz outros benefícios. Além disso, o trabalhador pode respeitar o seu relógio biológico, de acordo com o período em que se sente melhor para realizar suas atividades (Mill, 2012).

Por outro lado, um ponto que merece ser indicado, como desvantagem desse modo de trabalho, se refere, também, ao fenômeno da flexibilização das relações laborais. Essa questão enseja uma antítese nas análises aqui expressas, mas deve-se salientar que, assim como o trabalhador goza de uma maleabilidade para organizar sua jornada, ele deve aprender a gerenciar o seu tempo dedicado às atividades laborais com outros tempos sociais (tempo livre, lazer, tempo de formação e outros). Em uma sociedade onde o trabalho ainda ocupa um papel central na integração das relações sociais (Paugam, 2000), essa estruturação faz com que esse exercício de gerenciamento temporal se torne mais complexo.

Seguindo essa linha de pensamento, os entrevistados expuseram que a estruturação de suas jornadas laborais, tendo em vista essa realidade da flexibilização, Ihes permite realizar outras atividades. A maioria dos professores tutores participantes da pesquisa relatou ser possível se ajustarem a outras realidades profissionais.

[...] A gente tem outras atividades. Geralmente, eu desempenho minhas atividades a distância à noite. [...] terminou o meu horário, que é geralmente, às oito da noite, é que viria à nossa plataforma (T01).

[...] E é como eu te disse, eu normalmente escolho os dias. Quando eu não tinha entrado no doutorado eu ia pra qualquer lugar que estivesse precisando de tutor, aceitava ficar com disciplinas em qualquer interior. Ia pra Quiterionópolis que são sete horas, ia muito pra Camocim, Meruoca, que são locais mais distantes e de mais difícil acesso (T07).

Ante essa possibilidade associada à organização de trabalho flexível, observou-se que os professores tutores participantes, em sua maioria, possuem outras ocupações. As atividades laborais na EAD costumam ser desenvolvidas num período, considerado atípico, ou seja, geralmente durante o turno da noite, finais de semana e outros momentos, ou seja, no contrafluxo do horário das atividades mais estáveis que eles estão desenvolvendo paralelamente à da EAD. Esse aspecto pode estar restrito ao fato de esses participantes, por já terem 
outras ocupações que consideram ser "principal", pela configuração do vínculo laboral (a existência mínima de direitos trabalhista), deslocam as tarefas empreendidas na EAD para um plano "secundário", em virtude da circunstância de fragilização trabalhista que essa organização laboral Ihes impõe.

Para os participantes da pesquisa, o fato de eles poderem estruturar sua jornada de trabalho conforme suas necessidades e, ainda, não existir aquela figura de um chefe pressionando a toda hora e a todo o momento, representa um importante atrativo para optarem por essa modalidade educacional, referindo-se à função de tutor. Porém, essa realidade laborativa mostra-se complexa e ambígua. Se, de um lado, esse contexto deve realçar uma redução na capacidade da divisão do trabalho entre os que concebem e os que executam as atividades laborais, de outra parte, as repercussões dessa integração favorecem a manutenção do processo de racionalização do trabalho, um elemento marcante na organização produtiva industrial.

\section{Os Professores Tutores num Âmbito de Racionalização do Trabalho}

A inserção de estratégias flexíveis ao âmbito laboral permite, no primeiro plano, maior liberação da situação de trabalho, ou seja, aquelas regras e diretrizes implícitas às tarefas se tornam mais maleáveis para o trabalhador. No plano seguinte, essa realidade não pode ser considerada sinônimo de liberdade, pois essa noção de maleabilidade, geralmente, está associada a outras configurações de controle, ou, por assim dizer, de racionalização do trabalho.

[...] As atividades são organizadas de acordo com o professor. Nossa participação é estar lá, num determinado tempo (T08).

[...] Eu organizo os meus horários sem que aquela pessoa que está acima de mim perceba que estou deixando de lado algumas de minhas atividades (T06).

Os professores tutores levantaram essa problemática, quando trouxeram questões sobre o processo de trabalho no exercício da tutoria. A própria noção de polidocência, por exemplo, fragmenta as atividades laborais e viabiliza condições para que haja uma limitação de atuação desse profissional, que necessita seguir estritamente determinada diretriz. Esse conceito envolve um grupo de profissionais, composto, em sua maioria, por coordenadores e tutores, que atuam segmentadamente e de maneira colaborativa, representando a estrutura docente da Educação a Distância (EaD) (Mill, 2012).

Isso denota indícios de um jeito de especialização da tarefa (Lojkine, 1995), na qual o trabalhador é tratado, apenas, como uma engrenagem do sistema produtivo, passivo e desencorajado de tomar iniciativas. Suas ações se tornam reduzidas diante do processo de trabalho. É sabido que as atividades ligadas à área da EAD, geralmente, possuem uma formatação previamente concebida de atuação. O tutor executa sua função com base num conjunto de tarefas que, antecipadamente, já foi estruturada por outros profissionais. Ele 
recebe uma agenda (como um plano de aula) que contém todas as determinações a serem seguidas durante a disciplina (períodos de abertura dos fóruns, dos chats, de entrega dos portfólios, das avaliações e outros).

O fórum é um meio de comunicação assíncrona. Ele pode constituir-se sob distintas maneiras (temas para discussão, tópicos de respostas e outras) e funcionar como um critério de avaliação no processo de ensino e de aprendizagem da EAD. O chat é um recurso que favorece a comunicação síncrona entre professor e aluno, em tempo real. O período no qual o chat fica ativado on-line pode ser agendado, ou seja, esse instrumento possui horário de início e fim. Outro elemento do contexto da modalidade a distância é o portfólio, que se refere aos trabalhos individuais elaborados pelos alunos. Esses são realizados por meio de escrita dissertativa on-line, cujas notas ficam disponíveis virtualmente para o estudante e para o professor.

Essa configuração de trabalho, de certo modo, prescreve em demasia as atividades do professor tutor. Conforme o que descrevem, se uma turma, por exemplo, tivesse dificuldades numa determinada matéria, não poderia dedicar mais tempo naquele assunto, pois precisava seguir um cronograma previamente elaborado. Isso denota uma falta de autonomia durante a execução de suas tarefas. O tutor deve receber as instruções e, por conseguinte, se preparar para o início da disciplina, sabendo que nenhuma das alterações de que necessite pode ser feita. Fica para ele a possibilidade de ajustar algum déficit durante 0 semestre, por meio do calendário de algum encontro presencial. A realidade de trabalho que se mostra indica elementos que envolvem a padronização dos níveis operacionais da tarefa (Coriat, 2008) no contexto da Educação a Distância, o que se traduz em mais um modo de racionalização do processo de trabalho, ou seja, em outra maneira de manutenção do controle das atividades no âmbito laboral.

O professor coordenador da disciplina, figura presente na chamada polidocência, fica responsável pelas atividades de uma equipe de professores tutores. Esse profissional acompanha a execução das tarefas de tutoria daquela disciplina específica, estruturada por ele, ou não. Por exemplo, ela pode estar sendo ofertada em diferenciados polos, mas, mesmo assim, sendo necessário monitorar essas atividades que são ministradas por seu grupo (distintos tutores lotados em variados polos).

Esse expediente de regular o trabalho ocorre de maneira on-line, onde ele tem acesso ao sistema dos tutores, podendo visualizar se as atividades estão seguindo o cronograma, se a relação entre tutor e alunos está ocorrendo satisfatoriamente, além de verificar se a aplicação do conteúdo está de acordo com a proposta. Também exerce a função de auxiliar o professor tutor, em caso de dúvidas ou dificuldades que venham a surgir no decorrer da disciplina.

[...] No sistema o coordenador da disciplina também está lá. Ou seja, eu não estou sozinha com os alunos, ela também está nele, na 
plataforma virtual. Ela também pode ver tudo que está acontecendo lá (T05).

[...] O formador vem nos acompanhando. (...) eles querem que nós entremos todos os dias no sistema (T04).

Ao discutir essa temática acerca das questões que envolvem o controle, sobre essa realidade de trabalho contemporânea, Grisci (2008) refere um poder que se dilui por meio dessas estruturas flexíveis, produzindo uma espécie de sensação de liberdade para com o trabalhador, na qual, "aparentemente", não haveria mais uma imposição que o submetesse às regras fixas e incontestáveis no ambiente de trabalho. Principalmente, no período da sociedade industrial, os processos de saber e de poder tendiam a caminhar em direção a uma maneira específica de disciplina. Se naquela época a prática disciplinar visava, fundamentalmente, ao corpo, por meio de ações rígidas, normalizadoras e reguladoras, agora já não é bem assim, o objetivo é exercer um controle revestido por um discurso pautado na autonomia e na liberdade (Foucault, 1999).

A noção de liberdade e autonomia, geralmente, se vincula à ideia de resultados e metas. A fixação de uma estrutura preestabelecida, ou seja, com todas as atividades e os produtos finais já propostos, antecipadamente, faz com que os trabalhadores busquem atingi-los a todo custo. Nessa situação, ele passa a se gerir, uma vez que a tarefa já está previamente estabelecida (Sennett, 2006).

O fato de haver um investimento para o trabalhador internalizar esse autocontrole e automonitoramento, para a execução das suas atividades, não quer dizer que não existam técnicas de controle que o gerenciem externamente. Dadas essas considerações, é possível mencionar alguns exemplos que expressam essas estratégias aplicadas pelas organizações, para exercer sua vigilância sobre os empregados: tarefas realizadas com prazos estabelecidos, as atividades laborais de grupos precisam ser repassadas (copiado em todos os emails) para o gestor, avaliações (com critérios pouco delimitados e feedbacks explorados de maneira ineficiente) e outras.

É importante frisar que essa estrutura laboral institui uma dificuldade de conciliar satisfatoriamente trabalho e vida privada. Um dos aspectos que emergiu durante as entrevistas realizadas com os professores tutores se refere à gerência do tempo, nesse modelo de relações flexíveis de trabalho. Como não existe um demarcador temporal, que viabilize essa separação jornada laboral-tempo livre, o profissional de tutoria traz para si essa responsabilidade de conciliação entre suas atividades.

Por meio das entrevistas, emergiu uma temática que é muito cara para os profissionais que trabalham sob uma estrutura laboral flexível, qual seja, a conciliação entre o tempo de trabalho e o tempo de não-trabalho. As execuções 
das atividades de tutoria costumam exigir do tutor uma dedicação que é distribuída por toda a semana e finais de semana.

\section{Articulando Tempo de Trabalho e Tempo de Não-Trabalho}

Torna-se importante salientar o fato de que disciplinas são organizadas sob uma estrutura curricular modular, ou seja, elas existem um tempo de duração mais curto se comparadas àquelas que são estruturadas com apoio em paradigma semestral. No primeiro caso, a média é de 45 (quarenta e cinco) dias de aulas corridas, independendo de finais de semana e feriados. Na segunda, o tempo é mais longo, chegando a durar cerca de seis meses de período letivo. Vale destacar o fato de que esses formatos são escolhidos pela coordenação do curso, antes do início da disciplina ir ao ar na EAD (estar disponível on-line).

[...] As aulas acontecem em um período determinado. Por exemplo, uma disciplina pode começar hoje, ela vai ter quinze dias de duração. Nesses quinze dias são contados feriados, finais de semana e tudo (T02).

[...] Se você não tiver cuidado você acaba "misturando" toda a sua vida pessoal com a vida profissional. Mas, da mesma forma que atrapalha você também pode organizar os seus horários, para que as coisas acabem fluindo e não atrapalhem mais (T03).

Os participantes da pesquisa expressaram que, desde o momento em que se iniciam os trabalhos com uma turma on-line, precisa-se planejar para todos os dias em que a disciplina estiver no ar. É necessário reservar um determinado horário para os alunos e, principalmente, ter o cuidado para não acumular tarefas, pois, caso isso aconteça, as atividades passarão a exprimir maior probabilidade de afetar sua vida cotidiana, seus outros tempos sociais (família, lazer, ócio) e outros trabalhos também.

Eles deixaram claro que, certamente, algumas tarefas atrasam, pois, geralmente, os portfólios demandam mais tempo para correção. O professor tutor necessita ler, corrigir e devolver para cada um dos alunos esses trabalhos, o que demanda certo tempo para acontecer, levando essas atividades a extrapolar o horário reservado para o ensino a distância.

[...] E aí, lógico que afeta também o meu final de semana. Às vezes, preciso marcar um chat à tarde, ou tenho que marcar um chat durante a sexta à noite. Por esse lado, interfere (T10).

[...] Agora no Carnaval, todos os dias precisei entrar no sistema. Eu pensei: - ninguém vai me postar nada no carnaval. Porém, quando entrava era aquela demanda (T11).

O computador e/ou notebook são a principal ferramenta laboral desses profissionais, pois viabilizam o acesso ao trabalho em qualquer horário e em qualquer lugar. Chamam a atenção, entretanto, para o fato de que o contexto virtual de trabalho pode enganar muito, uma vez que as pessoas acreditam que sempre terão mais tempo para desempenhar suas atividades. 
Essas ferramentas são interpretadas pelos trabalhadores como meios que possibilitam a redução do tempo de trabalho, aumentam a velocidade na execução das atividades, permitem monitoramento mais eficaz e, acima de tudo, a simplificação de tarefas. Nesses processos, contudo, a introdução dessas tecnologias é capaz de permitir uma extensão do tempo de trabalho para as fronteiras do tempo livre, como feriados, fins de semana e os períodos noturnos, o que resulta num aumento desse tempo laboral (Adorno, 2002).

A temporalidade aufere uma conotação de não linearidade. Com isso, ela adquire uma representatividade que exige adaptação e maleabilidade. Vale salientar a ideia de que as características que se encontram nos quadros temporais modernos não desaparecem, contudo, começam a adquirir nova configuração, um reordenamento marcado por um tempo de delimitação difícil (Aquino, 2007).

[...] Eu procuro me organizar para que consiga ter esse momento de lazer, que é importante para todo trabalhador (T02).

[...] Ele não precisa interferir no seu lazer, tempo livre, etc. No começo ele interferia bastante, eu ficava naquela ansiedade, mas depois você pode se organizar, ou seja, da mesma forma que eu tenho aula na terça, de $18 \mathrm{~h} 30 \mathrm{~min}$ às $20 \mathrm{~h} 10 \mathrm{~min}$, tem um horário fixo, eu também posso ter no ensino a distância (T03).

Na contraposição dessas questões, observa-se que os professores tutores, em suas falas, também demonstram que podem administrar essa relação entre o tempo dedicado às suas obrigações laborais e o tempo liberado dessas imposições. Eles entendem que, durante a atividade de tutoria, saber gerenciar esses tempos é um importante aspecto para que possam desenvolver de maneira satisfatória suas tarefas, dentro e fora da sua jornada laboral. Salientam que esse exercício não é uma tarefa simples, pois demanda deles um movimento de reorganização de suas práticas diárias.

A ilustração de um período temporal muito bem delimitado, com horários de início, intervalo e fim, ainda é uma considerável referência em suas estruturações cotidianas. Aquele balizador que coordena e regula as atividades das pessoas, no caso, o trabalho, com suporte no modelo de sociedade industrial (tempos e espaços uniformes e fixos), tem ainda intensiva presença na organização do dia a dia (Aquino, 2007).

Nos discursos, os professores tutores exibira questões relativas à sua condição profissional na Educação a Distância. Esse aspecto ganhou um destaque nas falas desses trabalhadores, o que direcionou a atenção deste pesquisador para a estrutura de seus vínculos laborais.

\section{A Realidade do Professor Tutor}

Os profissionais salientaram que não existe um contrato que formalize a atribuição do professor tutor, com normas e diretrizes que legalizem e forneçam a eles garantias e benefícios trabalhistas. O que fazem é assinar um termo junto 
à Instituição de Ensino Superior (IES), em virtude da concessão da bolsa de fomento, de valor referente à $\mathrm{R} \$ 765$ (setecentos e sessenta e cinco reais) mensais, pelo período de exercício da função, conforme disposto em Resolução do Fundo Nacional de Desenvolvimento da Educação (FNDE) no 8, de 30 de abril de 2010. A ilustração dessa quantia decorre do fato de se estar falando da atividade de tutoria, pois essa quantia poderia ser objeto de uma variação, a depender da categoria a que se está referindo, no âmbito da EAD.

[...] Nós recebemos bolsas, que podem ser acumuladas, mas não são pagas todas simultaneamente. Elas não podem se chocar. Às vezes nós demoramos um período de seis meses para poder receber. Por exemplo, se eu tiver duas disciplinas aqui, eu não posso receber duas bolsas ao mesmo tempo, no mesmo mês (T04).

[...] A gente não tem vínculo, na verdade. Nós somos bolsistas. Então a gente só tem vínculo enquanto estiver trabalhando. Não estando trabalhando, então... Semestre que vem pode não ser ofertado, pelo fato da demanda ser menor. O fato de você não ter vínculo, não é um emprego seguro (T01).

Os professores tutores, em seus discursos, trouxeram sua condição de bolsista como algo desfavorável no exercício da tutoria. Essa realidade os situa numa posição em que não possuem nenhum benefício social (previdenciário), que formalize algum tipo de garantia trabalhista (aposentadoria, férias, licençamaternidade etc.). Para eles, essa atribuição não oferece nenhuma segurança trabalhista, haja vista o caráter temporário e não protetivo (regulamentado juridicamente) da bolsa. Acrescentam, ainda, fazendo referência a outro momento histórico, que aqueles trabalhos estáveis, que duram a vida inteira, parecem estar desaparecendo ou ficando mais difíceis de obter.

Esses aspectos revelados pelos professores tutores apontam indícios de precariedade das relações de trabalho, haja vista essas condições desfavoráveis (situação de risco, fragilidade dos vínculos laborais, ausência de proteção trabalhista) serem destacadas por meio dos discursos dos participantes da pesquisa. E claro que, quando se menciona esse termo precariedade, sabe-se que seu significado é amplo, pois pode, por exemplo, remeter a uma condição social, cujo olhar estaria voltado para aquelas pessoas que se encontram em situação de vulnerabilidade, exclusão e pobreza.

Baseado no posicionamento de Aquino (2008), um dos pontos que têm chamado a atenção é a diferenciação entre esses termos: precarização e precariedade. Um se refere ao fenômeno que acompanha as transformações na realidade de trabalho, do ponto de vista processual e histórico. O outro diz respeito às condições laborais com traços de vulnerabilidade e insalubridade, aspectos não exclusivos do momento histórico atual, mas comuns aos mais distintos contextos de trabalho.

A constituição da função de tutores é relatada dentro de um novo modelo de regulação que repercute no contexto da seguridade social do trabalhador, 
promovendo a quebra daquelas diretrizes normativas que substanciavam e favorecia a estabilidade do emprego, tão vinculada à ideia da sociedade salarial (Castel, 2015). Essa nova conjuntura socioeconômica é associada aos modelos de contrato de trabalho, amplamente estruturados mediante tempos flexíveis (contratos curtos; contratos de meio período; salário definido pela produtividade individual ou por metas, e outras).

Nas falas dos professores tutores essas características, comuns às modalidades ocupacionais contemporâneas, emergiram como um fator determinante para que os profissionais em questão buscassem incorporar, ao seu dia a dia, outras realidades de trabalho. A questão de precisarem complementar suas rendas, para suprir uma carência salarial, se tornou um aspecto constante em seus diálogos.

[...] Num primeiro momento aceitei a disciplina a distância para complementar minha renda. Mas reconheço que este não deve ser o principal incentivo. Esse vínculo, nós poderíamos dizer que é temporário (T02).

[...] Normalmente, nós tutores temos outros trabalhos. A atividade de tutoria é um extra. Então, no caso eu estou fazendo um doutorado, tenho a bolsa de doutorado, trabalho com atividades extras, como correções, formatação e revisão de textos e tenho a tutoria (T08).

A remuneração, nesse tipo de trabalho mais flexível, costuma ser baixa, quando comparada aos empregos de jornadas completas ou integrais (Pagán, 2007). Esse modelo proporciona ao empregado um aumento na sua jornada de trabalho, uma vez que buscará outras ocupações, tendo em vista agregar opções financeiras. Vale ressaltar que essa conjuntura proporciona, para a pessoa, o aumento de sua jornada de trabalho e, por sua vez, a maximização de sua condição precária (Antunes, 2015).

Os professores tutores explicitam a necessidade de não poderem desempenhar somente a função de tutoria, o que é uma perda para o sistema educacional da EAD. Os entrevistados destacam que o vínculo laboral (bolsa) que possuem nessa função é de caráter temporário, pois a atividade só é remunerada na medida em que a disciplina seja ofertada. Conforme Aquino (2008), esse processo traz uma profunda marca de desqualificação profissional.

A função do professor tutor corresponde, para os participantes da pesquisa, uma modalidade de vínculo de trabalho que ainda necessita de uma ação mais comprometida por parte daquelas pessoas que criam e/ou operacionalizam as políticas públicas voltadas para a área da Educação. Em decorrência dessa realidade, os professores tutores, em seus discursos, suscitaram pontos implicados ao modo de como se percebiam no contexto da Educação a Distância (EAD). 


\section{Professores Tutores: Percepções de Si, no Contexto de Atuação da EAD}

Nas entrevistas, os professores tutores reforçam a noção de que, atualmente, a maioria dos docentes que atua nessa área desempenha trabalho por amor e porque reconhecem a importância desta função na sociedade. Os respondentes, entretanto, não excluem aqueles profissionais que estão na área somente pela necessidade, chegando a enfatizar que, caso surgissem outras possibilidades, já teriam abandonado o âmbito educacional.

[...] Eu acho que apesar de não ser a perspectiva de nossos governantes, eu acho que essa era para ser a área mais valorizada dentro do país, a questão de estímulo de verbas e coisas assim. Por que são através das mãos dos professores que saem todos os outros profissionais. Não existe um profissional que se faça sem um professor, nenhum, nenhum, nenhum (T01).

[...] Às vezes percebo que nossa área é esquecida. [...] acho que somos pouco valorizados por aqueles que fazem e que governam (T02).

A desvalorização do trabalho do professor é uma pauta que ocupa lugar central nas discussões acerca (não somente na EAD) da educação no Brasil. Não se pode esquecer de que houve avanços, mas também há de ser ter a consciência de que esses aspectos ainda precisam avançar mais e mais. $\mathrm{Na}$ maioria das vezes, ainda Ihes faltam condições para poderem exercer o ofício de professor.

As principais deficiências que surgiram nas falas dos professores tutores, a fim de ilustrarem essa realidade, foram: a falta de materiais, para desenvolverem sua práxis; a ausência de incentivos, tanto por parte dos governantes quanto pela sociedade como um todo; as péssimas condições que, às vezes, eles precisam enfrentar para poderem ministrar suas aulas; além dos salários que ainda estão abaixo daquilo que a profissão merece. Cientes desse contexto que acomete a prática docente, viu-se uma tendência, durante o processo de entrevistas, que parece ser generalizada, qual seja: o fato de os professores tutores narrarem a realidade da Educação a Distância (EAD) como um demonstrativo explícito dessa condição que o professorado brasileiro enfrenta na sociedade.

[...] Se você pegar à nível nacional a gente vê claramente algumas mudanças, poucas, sutis, mas algumas mudanças. Mas, em sua grande maioria, a figura do tutor ela não é uma figura visível. Porque se fosse uma figura visível essa voz seria escutada, mas ela não é (T07).

[...] Quanto à valorização do professor ou do profissional da educação a distância, ainda acho que tenha muitos degraus a serem subidos Muitos degraus mesmo. (T10).

Apesar da diferença que existe entre a atuação do docente e a prática de tutoria, o tutor se vê como um professor. E, como tal, eles salientam, por meio de seus discursos, que deve haver uma valorização de sua função, seja referente 
a uma representatividade institucional, seja relacionada à melhoria de seus salários (que estão abaixo do salário-mínimo instituído no Brasil), ou, ainda, com respeito à reformulação de seus vínculos laborais. Essa realidade, segundo eles, muitas vezes, favorece uma intensa rotatividade entre aqueles que exercem a prática de tutoria, dada a cristalização dessas condições não favoráveis para o profissional que atua na Educação a Distância (EAD).

Os professores tutores reforçaram, ainda, o fato de que os governantes deveriam levar em consideração alguns pontos que denominam como reais, do exercício prático de suas funções, tendo em vista usarem suas experiências a fim de melhorarem o funcionamento da dinâmica da Educação a Distância (EAD), uma vez que retratam a potencialidade que essa modalidade educacional tem e que pode oferecer ao contexto de ensino e de aprendizagem do País.

\section{CONSIDERAÇÕES FINAIS}

Com amparo nas informações fornecidas pelos professores tutores, viu-se que a estrutura da organização do trabalho e o dinamismo das relações interpessoais que compõem o funcionamento da EAD, desencadearam um reordenamento do tempo de labor. Esse processo ensejou repercussões nos modos de viver e subjetivar desses trabalhadores. Destaca-se o fato de que a diluição da temporalidade laboral dos professores tutores, em relação a outros tempos sociais (lazer, ócio, família, trabalhos e outros), cria, em alguns momentos, uma dificuldade de conciliar a coexistência dessas distintas realidades que, muitas vezes, aparecem sob um formato tensionado.

Evidencia-se, também, uma lógica diferenciada na organização desse tipo de trabalho, cujas configurações primam pela variabilidade e pela maleabilidade das relações. Isso induz a pensar sobre uma nova configuração de vínculo laboral na área da educação, no âmbito do Ensino Superior, pautada na flexibilização das relações de trabalho que, na maioria das vezes, ilustra a condição de precariedade desses profissionais.

O chamado teletrabalho desenvolve-se, predominantemente, fora no âmbito organizacional, podendo ser desempenhado em diferenciados espaços (casa, carro, praças e outros). Esse aspecto atrativo, na maioria das vezes, sugere certa comodidade para aqueles profissionais, cuja dinâmica laboral se estrutura sob essa perspectiva. Esta configuração de trabalho, entretanto, não deixa de possuir as suas armadilhas. A noção que o trabalhador tem de ausência de controle e de vigilância se torna ilusória, uma vez que essas modalidades se manifestam sutilmente.

Considera-se que as reflexões que envolvem o processo de flexibilização das relações laborais em que se situa este estudo, abrem caminho para outras possibilidades de investigação, as quais favoreçam o surgimento de variados questionamentos acerca dessa importante temática. 


\section{DECLARAÇÃO DE CONFLITOS DE INTERESSE}

Os autores declaram não haver conflitos de interesse.

\section{REFERÊNCIAS}

Alonso, E. (1998). La mirada cualitativa en Sociología. Madrid: Fundamentos. Adorno, T. (2002). Industria cultural e sociedade. São Paulo, SP: Paz e Terra. Alves, D. (2008). Gestão, produção e experiência do tempo no teleatendimento (Tese de Doutorado). Universidade Federal do Rio Grande do Sul, Rio Grande do Sul.

Alves, G. (2007). Dimensões da reestruturação produtiva: Ensaios de sociologia do trabalho. Bauru, SP: Praxis.

Alves, G. (2011). Trabalho e Subjetividade: O espírito do toyotismo na era do capitalismo manipulatório. São Paulo, SP: Boitempo.

Antunes, R. (2005). O caracol e sua concha: Ensaios sobre a nova morfologia do trabalho. São Paulo, SP: Boitempo.

Antunes, R. (2015). Adeus ao trabalho?: Ensaios sobre as metamorfoses e a centralidade do mundo do trabalho. São Paulo, SP: Cortez.

Aquino, C. (2007). Transformações no modelo industrial, 'novos' trabalhos e novas temporalidades. Psicologia \& Sociedade, 19(edição especial 1), 2128. doi:10.1590/S0102-71822007000400005

Aquino, C. (2008). O Processo de precarização laboral e a produção subjetiva: um olhar desde a psicologia social. O público e o privado, 1(11), 167-176.

Aquino, C. (2009). Reestruturação da temporalidade laboral a partir do discurso dos trabalhadores do turismo. Cadernos de Psicologia Social do Trabalho, 12(2), 271-283.

Bauer, M., \& Gaskell, G. (2002). Pesquisa qualitativa com texto, imagem e som: Um manual prático. Petrópolis, RJ: Vozes.

Belloni, M. (2003). Educação a Distância. Campinas, SP: Autores Associados.

Beriáin, J. (2009). Las formas complejas del tiempo en la modernidad. Acta Sociológica, 1(49), 71-99.

Castel, R. (2015). As metamorfoses da questão social: Uma crônica do salário. Petrópolis, RJ: Vozes.

Castells, M. (1999). Sociedade em rede. São Paulo, SP: Paz e Terra.

Coelho, A. (2012). Construção do discurso da sustentabilidade: Uma prática de análise sociológica do discurso no campo organizacional (Tese de Doutorado). Universidade Vale do Itajaí, Santa Catarina.

Conde, F. (2009). Análisis sociológico del sistema de discursos. Madrid: Centro de Investigaciones Sociológicas.

Coriat, B. (1976). Ciencia, tecnica y capital. Madrid: Aermann Blume Ediciones. 
Coriat, M. (2008). El Taller y el cronómetro: Ensaio sobre el taylorismo, el fordismo y la produção en massa. Madrid: Siglo XXI.

Ernst, M. (2003). La flexibilité du temps de travail: Entre autonomie et contraintes. Une étude de cas en Suisse (Tese de Doutorado). Université de Marne-la-Vallée, Paris.

Fontanella, B., Ricas, J., \& Turato, E. (2008). Amostragem por saturação em pesquisas qualitativas em saúde: Contribuições teóricas. Cadernos de Saúde Pública, 24(1), 17-27. doi:10.1590/S0102-311X2008000100003

Foucault, M. (1999). Vigiar e punir: Nascimento da prisão. Petrópoles RJ: Vozes.

Fundo Nacional de Desenvolvimento da Educação (FNDE) (2010). Resolução FNDE n०8 de 30 de abril de 2010. Recuperado de https://www.fnde.gov.br/fndelegis/action/UrlPublicasAction.php?acao=abrir AtoPublico\&sgl_tipo $=$ RES\&num_ato $=00000008 \&$ seq_ato $=000 \& v \mid r \_a n o=201$ 0\&sgl_orgao $=$ CD/FNDE/MEC

Garrido, A. (2006). Sociopsicología de trabajo. Barcelona: UOC.

Gasparini, G. (1996). Tempo e trabalho no ocidente. In J. F. Chanlat (Ed.), O indivíduo na organização (Vol. 03, pp. 111-126). São Paulo, SP: Atlas.

Grisci, C. (1999). Trabalho, tempo e subjetividade: Impactos da reestruturação produtiva e o papel da psicologia nas organizações. Psicologia: Ciência e Profissão, 19(1), 2-13. doi:10.1590/S1414-98931999000100002

Grisci, C. (2008). Trabalho imaterial, controle rizomático e subjetividade no novo paradigma tecnológico. RAE-eletrônica, 7(1). doi:10.1590/S167656482008000100005

Harvey, D. (2008). Condições pós-modernas: Uma perspectiva sobre as origens das mudanças culturais. São Paulo, SP: Loyola.

Iñiguez, L. (2004). Manual de análise do discurso em ciencias sociais. Petrópolis, RJ: Vozes.

Lencastre, D. (2012). Educação on-line: análise e estratégia para criação de um protótipo. In Júnior, J. \& Coutinho, C. (Eds.), Educação on-line: Conceitos, metodologias, ferramentas e aplicações (pp. 129-138). Curitiba, PR: CRV.

Lévy, P. (2011). O que é o Virtual? São Paulo, SP: Editora 34.

Lojkine, J. (1995). A Revolução Informacional. São Paulo, SP: Cortez.

Masi, D. (2001). O futuro do trabalho: Fadiga e ócio na sociedade pós-industrial. Rio de Janeiro, RJ: José Olympio.

Mill, D. (2012). Docência virtual: Uma visão crítica. Campinas, SP: Papirus.

Miguélez, F. (2004). La flexibilidade laboral. Trabajo: Revista andaluza de relaciones Laborales, 01(13), 17-36.

Nardi, H. (2006). Ética, trabalho e subjetividade: Trajetórias de vida no contexto do capitalismo contemporâneo. Porto Alegre, RS: Universidade Federal do Rio Grande do Sul.

Niles, J. (1976). Telecommunications - transportation tradeoff: Options for tomorrow. New York: John \& Sons. 
Pagán, R. (2007). Diferencias salariales entre el empleo a tiempo completo y parcial. Revista de Economía Aplicada, 15(43), 05-47.

Paugam, S. (2000). Le salarié de la précarité. Les nouvelles formes de I'intégration professionnelle. Paris: PUF.

Ponte, F. T. (2015). O (re)dimensionamento da temporalidade laboral na vivência de professores tutores da educação on-line. (Dissertação de Mestrado). Universidade Federal do Ceará.

Preti, O. (1996). Educação a distância: Inícios e indícios de um percurso. Cuiabá, MT: NEAD/IE - Universidade Federal de Mato Grosso.

Ruiz, R. (2009). Análisis Sociológico del Discursos: Métodos y Lógicas. Forum Qualitative Sozialforschung/Forum: Qualitative Social Research, 10(2). Recuperado http://www.qualitativeresearch.net/index.php/fqs/article/view/1298

Sato, L., Bernardo, M., \& Oliveira, F. (2008). Psicologia social do trabalho e cotidiano: A viência de trabalhadores em diferentes contextos micropolíticos. Psicologia para América Latina, (15). Recuperado de http://pepsic.bvsalud.org/scielo.php?script=sci_arttext\&pid=S1870$350 \times 2008000400010$

Sennet, R. (2006). A cultura do novo capitalismo. Rio de Janeiro, RJ: Record.

Sue, R. (1995). Temps et ordre social. Paris: PUF.

Zuin, A. (2006). Educação a distância ou educação distante? O programa Universidade Aberta do Brasil, o tutor e o professor virtual. Educação \& Sociedade, 27(96), 935-954. doi:10.1590/S0101-73302006000300014

Sobre os autores

Felipe Teófilo Ponte é psicólogo pela Universidade de Fortaleza, mestre em Psicologia pela Universidade Federal do Ceará. Pesquisador do Núcleo de Psicologia do Trabalho - NUTRA/UFC. Trabalha no campo da Psicologia Organizacional e do Trabalho. felipeponte25@yahoo.com.br.

Cássio Adriano Braz de Aquino é psicólogo pela Universidade Federal do Ceará, mestre e doutor em Psicologia Social pela Universidad Complutense de Madrid. Trabalha na linha de pesquisa Processos Psicossociais e Vulnerabilidades Sociais do Programa de Pós-Graduação em Psicologia da UFC, com foco nas transformações do mundo laboral. brazaquino@ufc.br.

Felipe Teófilo Ponte e Cássio Adriano Braz de Aquino participaram de forma equânime na contribuição da escrita do artigo.

Os autores agradecem ao Instituto Universidade Virtual da Universidade Federal do Ceará, em especial aos Professores Tutores pela participação na pesquisa. 
$1^{a}$ revisão em: 20/12/2016

$2^{a}$ revisão em: 06/03/2017

Aceito em: 24/03/2017 